
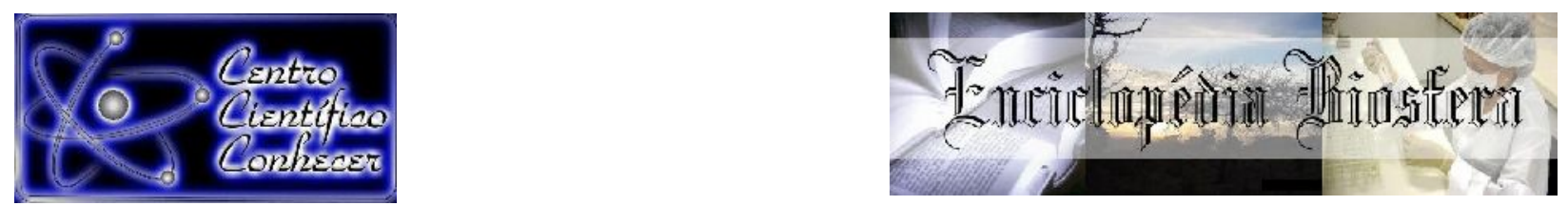

\title{
VIOLÊNCIA CONTRA MULHER E RAÇA: UMA ANÁLISE INTERSECCIONAL DA PANDEMIA DE COVID-19
}

\author{
Raíssa Ladislau Leite', Mônica de Almeida Vasconcelos', Alini Oliveira dos \\ Santos', Tâmara Karime Lima dos Santos', Laila Mayara Drebes² \\ ${ }^{1}$ Mestrandas do Programa de Pós-Graduação Dinâmicas Territoriais e Sociedade \\ na Amazônia (PDTSA) da Universidade Federal do Sul e Sudeste do Pará \\ (UNIFESSPA), Marabá, PA, Brasil. Bolsistas CAPES. E-mail: \\ raissaladislauleite@unifesspa.edu.br \\ 2 Doutora em Extensão Rural, Professora do Instituto de Estudos do Trópico \\ Úmido (IETU) e do PDTSA da UNIFESSPA, Xinguara, PA, Brasil.
}

Recebido em: 15/02/2021 - Aprovado em: 15/03/2021 - Publicado em: 30/03/2021

DOI: 10.18677/EnciBio_2021A15

\begin{abstract}
O debate sobre a violência contra a mulher tem se ampliado e disseminado pelos mais variados setores da sociedade no decorrer do último século. Não à toa, durante a pandemia de COVID-19 vivenciou-se um período não só de maior visibilidade de casos, como, também, de intensa preocupação com as mulheres vítimas de violência. Diante disso, o presente artigo se propõe a refletir sobre a violência contra a mulher no período de pandemia do novo coronavírus, enfatizando o fenômeno de subnotificações de casos e problematizando a invisibilidade racial das mulheres violentadas. Para tal intento, o estudo fez uso da ferramenta analítica chamada interseccionalidade. Foi realizada pesquisa bibliográfica e documental. Antes da COVID-19, a violência contra a mulher já representava um importante problema social e uma violação dos direitos humanos, o qual se agravou com as medidas de isolamento requeridas para conter a disseminação do novo coronavírus, pois as mulheres foram compelidas a passar mais tempo com seus companheiros, dificultando as denúncias e provocando subnotificação de casos. Não apenas, é importante observar o recorte racial das mulheres vítimas de violência, tendo em vista que as negras são as que se encontram mais vulneráveis, principalmente no contexto pandêmico, dadas as dificuldades de acesso a serviços de saúde, entre outras questões. É necessário que as políticas de combate à violência contra a mulher tenham como base as pluralidades que caracterizam as mulheres brasileiras, diferenças essas que não se restringem ao gênero, envolvendo diversas outras características, como é o caso da raça.
\end{abstract}

RESUMO

PALAVRAS-CHAVE: Coronavírus; gênero; isolamento social; mulheres negras; violência doméstica e familiar. 


\title{
VIOLENCE AGAINST WOMEN AND RACE: AN INTERSECTIONAL ANALYSIS OF THE PANDEMIC OF COVID-19
}

\begin{abstract}
The debate about violence against women has increased and disseminated to the most varied sectors of society during the last century. Not surprisingly, during the COVID-19 pandemic, there was a period not only of greater visibility of cases, but also of intense concern for women victims of violence. In view of this, the present article proposes to reflect on violence against women in the pandemic period of the new coronavirus, emphasizing the phenomenon of underreporting of cases and problematizing the racial invisibility of women victims of violence. For this purpose, the study made use of the analytical tool called intersectionality. Bibliographic and documentary research was carried out. Before COVID-19, violence against women was already a major social problem and a violation of human rights, which was aggravated by the isolation measures required to stem the spread of the new coronavirus, because women were compelled to spend more time with his partners, making denunciations difficult and causing underreporting of cases. Not only, it is important to observe the racial profile of women victims of violence, considering that black women are the most vulnerable, especially in the pandemic context, because the difficulties in accessing health services, among other issues. It is necessary that policies to combat violence against women are based on the pluralities that characterize Brazilian women, differences that are not restricted to gender, involving several other characteristics, such as race.
\end{abstract}

KEYWORDS: Coronavirus; genre; social isolation; black women; domestic violence.

\section{INTRODUÇÃO}

Além da crise sanitária que o mundo vivencia devido à pandemia de COVID19, muitos outros problemas sociais foram agravados pelo novo coronavírus. A humanidade está ainda mais exposta às deficiências existentes não somente no âmbito da saúde, mas na educação, na economia, na política, na segurança, etc., deficiências essas que têm como consequência o agravamento das desigualdades sociais. Assim, a COVID-19 tem sido pauta de discussões em todos os âmbitos da sociedade, aprofundando divergências entre cientistas, médicos e a população em geral, especialmente no Brasil (MONTEIRO et al., 2020b; VELOSO; MAGALHÃES, 2020).

A violência contra a mulher tornou-se um tópico ainda mais relevante em tempos de pandemia, sobretudo, porque a atual situação socioeconômica tende a piorar essa problemática. Segundo Monteiro et al. (2020b), a maioria das famílias economicamente vulneráveis são encabeçadas por mulheres e mais de $70 \%$ são negras. Deste modo é necessário refletir sobre a violência e suas nuances, em especial a violência contra a mulher e de como a questão racial vem sendo discutida em trabalhos produzidos sobre a temática nos últimos anos. As produções científicas são fundamentais para descrever, identificar, planejar e realizar ações, revelando a importância de estudos deste tema na elaboração e construção de referenciais teóricos, estratégias didáticas e produção de materiais sobre a violência de raça e gênero que auxiliem em ações que subsidiem os futuros trabalhos e políticas públicas para conter a violência contra a mulher (MONTEIRO et al., 2020a).

Este artigo objetiva refletir sobre a violência contra a mulher no período da pandemia de COVID-19 no Brasil, utilizando a ferramenta analítica da ENCICLOPÉDIA BIOSFERA, Centro Científico Conhecer - Jandaia-GO, v.18 n.35; p. 2012021 
interseccionalidade para discutir as subnotificações dos casos e problematizar a invisibilidade da questão racial nesse âmbito. Reivindica-se que a questão racial receba a devida atenção na produção de dados de violência contra a mulher e que seja tratada com a mesma seriedade que a própria questão de gênero, pois mulheres não negras e mulheres negras são afetadas de maneira distinta pela violência e pela própria pandemia.

Em termos metodológicos, a pesquisa teve caráter de cunho bibliográfico e documental. Entende-se por pesquisa bibliográfica a revisão da literatura sobre as principais teorias que norteiam o trabalho científico, a qual pode ser realizada com diferentes materiais, sejam artigos ou outras fontes (MARCONI; LAKATOS, 2018). Já a pesquisa documental, segundo Gil (2019), é fundamentada em arquivos institucionais conservados no interior de empresas, órgãos públicos e outras organizações que sofrem algum tipo de pesquisa e investigação.

A pesquisa bibliográfica foi realizada no Portal de Periódicos da CAPES, na modalidade artigos científicos na língua portuguesa, em textos publicados no período de 2017 a 2020 . Posto isto, foram buscadas fontes bibliográficas a partir das combinações das palavras-chave: violência contra a mulher, violência doméstica e violência de gênero; violência contra mulher e COVID-19; violência, mulheres negras e COVID-19; e interseccionalidade e COVID-19. A busca resultou em 23 fontes bibliográficas, destas, 18 artigos foram utilizados para a redação desse estudo, por convergirem com o objetivo, sendo que os critérios de exclusão foram: estudos repetidos e estudos que não incluíssem o objeto de pesquisa.

Para auxiliar no aprofundamento da discussão, foram incorporadas outras fontes bibliográficas, anteriores ao período pesquisado, que também discutiam de forma mais ampla a problemática da pesquisa, considerando que as pesquisas acadêmicas se atualizam e são paulatinamente estruturadas.

Para discutir como a pandemia afetou de forma desigual a população negra, contextualizando a interseccionalidade, foi aplicada a pesquisa documental, a qual foi baseada em documentos do Fórum Brasileiro de Segurança Pública, do Instituto Brasileiro de Geografia e Estatística e do Instituto de Pesquisa Econômica Aplicada. Também foram consultados documentos do governo federal, como legislações e sites de ministérios. Todos esses documentos trouxeram informações sobre a violência contra a mulher no Brasil, a questão racial dessa violência e a vulnerabilidade de mulheres e, principalmente, mulheres negras, no contexto da pandemia de COVID-19.

Tanto os dados bibliográficos como documentais levantados foram analisados conforme a metodologia de análise de conteúdo, por meio da qual os dados foram sistematizados e descritos, para posteriormente serem realizadas as inferências e interpretações (BARDIN, 2011).

Para atender ao objetivo proposto, o artigo foi organizado em três seções. A primeira discute a questão da violência contra a mulher no Brasil e a relaciona com a interseccionalidade para apresentar a importância da questão racial no contexto da pandemia. A segunda seção aborda a relação entre a pandemia de COVID-19 e a violência contra a mulher, enfatizando as subnotificações dos casos, sobretudo de vítimas negras. Já a terceira seção, debate especificamente a questão racial no contexto de violência contra a mulher vivenciada durante a pandemia. Por fim, as considerações finais procuram sintetizar as principais informações descobertas a partir do estudo. 


\section{REFLEXÕES SOBRE VIOLÊNCIA CONTRA A MULHER E INTERSECCIONALIDADE}

No Brasil, um momento histórico das reivindicações dos movimentos de mulheres aconteceu no ano de 1994, com a realização da Convenção Interamericana para Prevenir, Punir e Erradicar a Violência contra a Mulher, também conhecida como Convenção de Belém do Pará (CARNEIRO, 2017). Como resultado das articulações políticas realizadas nesta Convenção, anos mais tarde, um conjunto de organizações de mulheres elaborou uma proposta de projeto de lei para tratar da questão da violência contra a mulher. Essa proposta foi discutida e reformulada por um grupo de trabalho interministerial coordenado pela Secretaria Especial de Políticas para as Mulheres e foi enviada pelo Governo Federal ao Congresso Nacional, resultando na Lei no 11.340 de 22 de setembro de 2006, também conhecida como Lei Maria da Penha (BRASIL, 2006).

Campos et al. (2020) destacam que a promulgação da Lei Maria da Penha estimulou o aumento dos estudos sobre a violência contra a mulher. A Lei representa um marco jurídico-normativo para consolidar formas e instrumentos adequados para combater a violência doméstica e familiar, como destaca Martins et al. (2020). Mas apesar de apresentar medidas de prevenção muito bem delineadas no papel, a Lei Maria da Penha ainda precisa ser melhor consolidada, pois os resultados das pesquisas que se propuseram a avaliar a rede de enfrentamento engendrada pela Lei apontam que ainda são precários os recursos humanos especializados, a infraestrutura e a articulação dos serviços que a compõe. Ademais, são realizados poucos acompanhamentos e encaminhamentos de mulheres vítimas de violência, o que pode estar relacionado com a própria subnotificação dos casos (CURIA et al., 2020).

Segundo 0 art. 5 da Lei Maria da Penha, a violência doméstica e familiar contra a mulher se configura como "qualquer ação ou omissão baseada no gênero que lhe cause morte, lesão, sofrimento físico, sexual ou psicológico e dano moral ou patrimonial" (BRASIL, 2006). Além do mais, essa violência está relacionada com estupro, abuso sexual, tortura, tráfico de mulheres, prostituição forçada, sequestro e assédio sexual, inclusive se perpetrada ou tolerada pelo Estado e seus agentes (OKABAYASHI et al., 2020). Sendo assim, a violência contra a mulher assume expressões variadas, pois a agressão contextualizada pelas relações de gênero, que se produz e reproduz no âmbito do sistema patriarcal, fundamenta atos sociais derivados da hierarquização naturalizada de gênero e do sexo, que supervalorizam atributos considerados masculinos (CARNEIRO, 2017).

De acordo com Campos et al. (2020), a amplitude da violência de gênero é perceptível na história de vida de pessoas em relacionamentos violentos e existe relação entre violência conjugal e experiências de violência na família de origem, tanto de homens, quanto de mulheres. Além disso, Curia et al. (2020) ressaltam que as consequências da violência contra a mulher incluem agravos significativos de saúde física e mental das vítimas, com efeitos de médio e longo prazo, do tipo crônicos, podendo resultar em lesão corporal e óbito. Carneiro (2017) acrescenta que as consequências ultrapassam a dimensão individual, afetando relações familiares e sociais, produzindo isolamento social e prejuízos no exercício de atividades laborais e no acesso ao cuidado.

Todavia, a violência contra as mulheres não se restringe a uma questão de gênero. As sociedades atuais são constituídas por estruturas de dominação duradouras, produzidas historicamente e reproduzidas de modo objetivo e subjetivo 
nas relações sociais. Embora o patriarcado e a dominação masculina nele entranhada constituam uma dessas estruturas, ela não é a única, pois:

\begin{abstract}
$\mathrm{Na}$ sociedade de classes, a violência contra as mulheres é produto não apenas do patriarcado, mas da imbricação com outros sistemas de hierarquia e dominação ou sistemas estruturantes: o racismo e o capitalismo. Nessa perspectiva, tais sistemas se consubstanciam na chamada sociedade patriarcal-racista-capitalista, que produz as relações sociais de sexo/gênero, classe, raça/etnia e, consequentemente, a exploração-opressão que dela deriva. Logo, a violência contra as mulheres não é apenas produto: é, do mesmo modo, condição para tais relações e, portanto, condiciona a experiência feminina (BARROSO, 2019, p. 142).
\end{abstract}

O reconhecimento da existência de inúmeras características importantes na compreensão do fenômeno de violência contra a mulher, chama a atenção para uma certa invisibilidade das questões de classe e de raça no modo como o País vem combatendo em termos jurídicos-normativos a violência doméstica e familiar. Como destacado por Curia et al. (2020), a violência contra a mulher não seleciona cultura, etnia, religião, classe, raça ou escolaridade, e as experiências das mulheres mudam conforme suas condições de vida e de acesso a serviços de saúde e de segurança.

Diante disso, apesar da importância da Lei Maria da Penha para o combate da violência contra a mulher no Brasil, percebe-se uma generalização das mulheres vítimas de violência, que encobre questões fundamentais para compreender o fenômeno e evitá-lo. Para Barroso (2019), isso gera um distanciamento entre os dados oficiais e a realidade concreta das vítimas, posto que os registros não alcançam a multiplicidade de expressões da violência no cotidiano das mulheres.

É nesse ponto que se torna importante a ferramenta analítica da interseccionalidade para uma apuração mais precisa do fenômeno de violência contra a mulher. A partir do final do século $X X$, principalmente no decorrer das décadas de 1980 e 1990, inicia-se um questionamento da homogeneidade da categoria analítica mulher, que vinha sendo tratada como unívoca no seio dos estudos feministas até então: a categoria "mulher" continha em si, implicitamente, os qualificativos "branca" e burguesa" (VIGOYA, 2015).

Os estudos emergentes, conhecidos como "feminismo de cor", ao sistematizar as vivências de mulheres negras, indígenas, árabes e outras, desafiaram os critérios universais implicados na categoria analítica mulher, evidenciando a existência de outros sistemas de dominação que se cruzavam em seu interior, para além da relação de gênero (homem-mulher), como era o caso das relações de classe (ricopobre) e de raça (branco-negro) (VIGOYA, 2015). Ao argumentar sobre como os estudos feministas vinham ignorando a heterogeneidade das mulheres, fragmentadas e múltiplas, enquanto coletivo e indivíduo, o feminismo de cor contribuiu para a construção do que mais tarde se transformaria na ferramenta analítica de interseccionalidade.

Esse conceito foi elaborado pela advogada feminista afrodescendente Kimberlé Crenshaw, no fim dos anos 80, nos Estados Unidos. A intelectual mostrou que as leis estadunidenses não eram suficientes para abranger as múltiplas opressões sofridas pelas mulheres negras. Dessa maneira, no interior das comunidades negras norte-americanas, as mulheres eram pressionadas 
antagonicamente em relação aos casos de violência: enquanto os líderes dos movimentos negros as pressionavam para não denunciar, as líderes dos movimentos feministas as pressionavam para denunciar. Cada grupo buscava garantir a lealdade das mulheres negras às suas próprias causas (AKOTIRENE, 2019).

Com isso, Kimberlé Crenshaw procurou demonstrar como as mulheres negras não eram plenamente atendidas nem pelas políticas antirracistas, nem pelas políticas feministas, pois as suas experiências de opressão só eram compreendidas por meio da percepção da coexistência de distintas situações de dominação. Daí o termo interseccionalidade, que alude à ideia de pertencimento a dois ou mais conjuntos (AKOTIRENE, 2019).

Dessa maneira, de acordo com Vigoya $(2015 ; 2016)$, interseccionalidade é um conceito utilizado para designar uma perspectiva teórica e metodológica concentrada sobre as interconexões das relações de poder e das opressões cruzadas, principalmente de classe, de raça e de gênero, que não costumam acontecer isoladas umas das outras. Ainda conforme Vigoya (2015), como o gênero trata de relações de poder, faz referência aos homens e às mulheres já inscritos em relações sociais de classe e raça. Os pares "homens-mulheres, "branco-negros" e "rico-pobres" devem ser pensados como antagonismos entrecruzados que constituem a trama de relações de poder. Assim, as relações de classe, raça e gênero não são universos de experiências isoladas umas das outras, mas que existem nas e através das outras, mesmo se em termos contraditórios e conflituosos.

O conceito de interseccionalidade é uma ferramenta analítica interessante porque, na visão de Vigoya (2015), permite e favorece a construção de um campo de conhecimento que comporta as exclusões, os interditos e as dissimulações em termos de relações de poder. Nos termos de Oliveira (1998, p. 91), "juntamente com as questões de classe e raça, as relações de gênero compõem a tríade analítica que ajuda a esclarecer os mecanismos pelos quais poder e recursos são socialmente distribuídos".

\begin{abstract}
A interseccionalidade visa dar instrumentalidade teórico-metodológica à inseparabilidade estrutural do racismo, capitalismo e cisheteropatriarcado produtores de avenidas identitárias em que mulheres negras são repetidas vezes atingidas pelo cruzamento e sobreposição de gênero, raça e classe, modernos aparatos coloniais (AKOTIRENE, 2019, p.19).
\end{abstract}

Diante do exposto, os obstáculos resultantes da pobreza e do racismo fazem com que mulheres negras vivenciem em seu cotidiano múltiplas formas de violências, para além do machismo. Entre estas, destacam-se as dificuldades de acesso aos serviços de saúde, o que reflete na baixa atenção às especificidades da saúde das mulheres negras e suas demandas (CARNEIRO, 2017). Por este ângulo, ainda que exista legislação e estudos para contribuir no enfrentamento da violência, há invisibilidade nos casos de violência contra a mulher, dada a falta de clareza referente à questão de classe e de raça.

RELAÇÃO ENTRE PANDEMIA E CASOS DE VIOLÊNCIA CONTRA A MULHER

No Brasil, apesar da Lei Maria da Penha, os casos de violência contra a mulher têm crescido constantemente nos últimos anos, sendo que o principal agressor identificado é o parceiro ou ex-parceiro íntimo. No contexto pandêmico, ENCICLOPÉDIA BIOSFERA, Centro Científico Conhecer - Jandaia-GO, v. 18 n.35; p. 205 2021 
para controlar a transmissão do novo coronavírus, a Organização Mundial da Saúde orientou que fossem adotadas medidas de isolamento social, as quais foram colocadas em prática no território brasileiro por forças governamentais dos mais diversos níveis: federal, estadual e municipal. Antes da pandemia de COVID-19, a violência contra a mulher já representava um importante problema social e uma violação dos direitos humanos, mas se agravou ainda mais no período pandêmico. Ao se considerar as medidas de isolamento social, subentende-se um maior convívio entre familiares residentes em um mesmo domicílio. Esta situação pode culminar em problemas de relacionamento, dentre estes, a violência contra a mulher (MARTINS et al., 2020).

As medidas de isolamento social contribuíram para aumentar a exposição das mulheres ao risco de violência doméstica e familiar, uma vez que muitas passaram a estar o tempo todo em casa sob a vigilância de seus agressores. A busca pelo auxílio se tornou dificultada, não apenas pela presença constante do agressor, mas pela própria redução das atividades dos serviços de apoio às vítimas, em virtude das medidas de quarentena, como setores de assistência social, saúde e segurança pública. Vale destacar, também, que as instituições de saúde redirecionaram sua atenção prioritária para o atendimento de casos suspeitos e confirmados de COVID19, secundarizando a preocupação com o atendimento de mulheres vítimas de violência. Outro fator que dificultou o processo de busca por ajuda foi o próprio medo de exposição ao coronavírus e possível contágio pela COVID-19 (MARTINS et al., 2020).

Para Martins et al. (2020), a tendência de violência contra a mulher no contexto de quarentena é maior em situações em que a mulher passa a trabalhar em casa ou tenta manter a renda por meio de trabalhos informais, ao passo que as tarefas domésticas se multiplicam conforme mais pessoas ficam em casa por um período também maior. A sobrecarga de trabalho feminino nos cuidados com a casa, filhos, outros familiares, além do trabalho doméstico e de seu próprio trabalho remunerado, podem reprimir a capacidade das mulheres de esquivarem-se de conflitos com seus agressores, tornando-as mais sujeitas à violência psicológica e à coerção sexual.

Em somatório, Martins et al. (2020) destacam ainda outros fatores que contribuem para reprimir as mulheres no contexto da pandemia, como é o caso do desemprego, perda do sustento e dependência financeira, que se tornam obstáculos capazes de impedir que a mulher rompa a relação abusiva na qual se encontra. $O$ aumento do consumo de bebidas alcóolicas e até mesmo de drogas ilícitas por parte dos agressores também é um agravante. Embora o isolamento social por si só não produza a violência, ele dá visibilidade às relações de poder historicamente construídas, que provocam a intersecção da questão de gênero, de raça e de classe (GONZAGA: CUNHA, 2020).

O isolamento social por si só não ocasiona a violência, mas tem a potência de colocar em evidência as vivências dessas mulheres em situação de violência doméstica e de desvelar o machismo estrutural como real gerador da violência, dando ênfase às desigualdades raciais, de gênero e de classe social, além das opressões decorrentes das relações dentro do sistema patriarcal, estruturado historicamente na sociedade brasileira, e que tem impactos deletérios, particularmente sobre as mulheres. (BARBOSA et al., 2020, p.10). 
Assim, como afirmaram Veloso e Magalhães (2020, p.13), a pandemia "apenas intensificou a violência de gênero ao forçar o confinamento de mulheres com parceiros agressivos que exercem sobre elas um controle exacerbado diante da sensação de maior impunidade provocada pelo isolamento". Diante do recolhimento, de portas fechadas, de gritos não ditos, é que a proporção da violência aumenta. Como o agressor convive com a vítima, muitos desses crimes são subnotificados, e as leis contra a violência doméstica e familiar e as leis do feminicídio não conseguem inibir e muito menos conter a tendência de aumento da violência contra a mulher (VELOSO; MAGALHÃES, 2020).

Segundo a Pesquisa Visível e Invisível - A Vitimização de Mulheres no Brasil, $2^{2}$ Edição (2019, p.45), "ainda que seja constitucionalmente entendida como o 'asilo inviolável do indivíduo', é na própria casa que $42 \%$ das mulheres entrevistadas foram agredidas. "É justamente nesse lugar que "não há testemunha, não há possibilidade de fuga, não há como esta mulher ser socorrida, ainda mais se pensarmos na perspectiva cultural que reverbera até hoje em nossa sociedade de que ali, não nos é permitido intromissão" (FBSP, 2019b, p. 45).

Segundo dados do site do Ministério da Mulher, da Família e dos Direitos Humanos, o número de denúncias feitas à Ouvidoria Nacional de Direitos Humanos teve um aumento médio de $14,1 \%$ nos primeiros quatro meses do ano de 2020 , em comparação ao mesmo período do ano anterior. O total de registros foi de 32,9 mil entre janeiro e abril de 2019 contra 37,5 mil no mesmo período de 2020, com destaque para o mês de abril, que apresentou um aumento de $37,6 \%$ no comparativo entre os dois anos (BRASIL, 2020).

Durante a progressão da pandemia se intensificou a subnotificação dos casos de violência contra a mulher. Em virtude disso, os números oficiais não refletem a realidade dos casos no Brasil. Muitas mulheres vítimas de violência não entraram nas estatísticas oficiais. Esse cenário favoreceu e continua favorecendo a impunidade e o agravo dos atos violentos (AGÊNCIA BRASIL, 2020).

De acordo com dados do Fórum Brasileiro de Segurança Pública (FBSP, 2020), embora a quarentena seja uma medida de segurança necessária para minimizar os efeitos diretos da COVID-19, pode-se sugerir que o isolamento social tem imposto uma série de consequências para a vida de milhares de mulheres que já viviam em situação de violência doméstica e familiar, e que uma das consequências diretas dessa situação tem sido a diminuição das denúncias.

$\mathrm{Na}$ nota técnica Violência Doméstica durante a Pandemia de COVID-19 (FBSP, 2020), são encontrados dados sobre o número de boletins de ocorrência referentes aos casos de violência contra a mulher, comparando os anos de 2019 (antes da pandemia) e de 2020 (durante a pandemia). Os dados evidenciam a queda no número de boletins de ocorrência ao comparar março de 2019 e março de 2020. Assim, os primeiros dias de isolamento social já foram suficientes para imprimir a queda das denúncias de violência doméstica e familiar: $-29,1 \%$ no Ceará, $-28,6 \%$ no Acre, $-21,9 \%$ no Mato Grosso, $-13,2 \%$ no Pará e $-9,4 \%$ no Rio Grande do Sul.

Para auxiliar o entendimento sobre o debate de violência contra a mulher e COVID-19, reflete-se que não há uma linha de argumentação concreta que relacione a pandemia ao aumento da violência de gênero. O que se pode verificar é a evidente diminuição pela busca dos serviços de atendimento e proteção às mulheres, o que oculta dados dessa realidade. Fato que apenas enfatiza ainda mais a problemática causada pela (in)visibilidade histórica da violência doméstica e familiar e a ENCICLOPÉDIA BIOSFERA, Centro Científico Conhecer - Jandaia-GO, v.18 n.35; p. 2072021 
subnotificação desse tipo de crime: em um momento que se debate questões de saúde pública e proteção à vida através do isolamento social, milhares de mulheres vivem um verdadeiro terror sob essas condições (BARBOSA., et al., 2020).

Diante desse cenário, o governo federal promulgou a Lei ํㅜ 14.022/2020 para fortalecer a prática de registro de ocorrência policial on-line e expedição de medidas protetivas por meios digitais (BRASIL, 2020). Segundo a Secretaria Nacional de Políticas para as Mulheres do Ministério da Mulher, da Família e dos Direitos Humanos, essa legislação foi importante para garantir o funcionamento dos serviços da rede de apoio às mulheres vítimas de violência em tempos de pandemia (BRASIL, 2020).

O Ministério da Mulher, da Família e dos Direitos Humanos, dentre suas iniciativas, elaborou um aplicativo para denúncia dos casos de violência contra a mulher e ampliou os atendimentos do Ligue-180. No site do Ministério também existe atendimento por chat, com acessibilidade para a Língua Brasileira de Sinais (LIBRAS). É possível também requerer atendimento pelo aplicativo Telegram. Há um conjunto de instituições e serviços do poder público para atender as mulheres em situação de violência, assim como seus filhos. No site do Ministério também são encontradas informações sobre os órgãos que podem ser buscados pelas vítimas. Além desse aparato digital, o Ministério produziu cartilhas destinadas ao enfrentamento da violência doméstica e familiar contra a mulher (BRASIL, 2020).

Além disso, o Ministério lançou uma campanha chamada "Alô Vizinho", cujo objetivo consiste em conscientizar a sociedade que em situação de violência contra a mulher, a sociedade precisa funcionar como uma rede de proteção e apoio, socorrendo as vítimas. A campanha incentiva a denúncia, garantindo a existência de meios que preservam o anonimato dos denunciantes. Essa campanha está em 10 estados brasileiros e tem a intenção de despertar o senso de urgência da população diante de casos de violência contra a mulher na vizinhança (BRASIL, 2020).

Segundo o documento Nota Técnica: Violência Doméstica durante a Pandemia (FBSP, 2020), realizada pelo Fórum Brasileiro de Segurança Pública, outras iniciativas têm sido implantadas pela sociedade civil organizada como forma de apoio às mulheres em situação de violência doméstica e familiar durante a pandemia. Como por exemplo, o \#TôComElas, iniciativa do Mapa do Acolhimento que surgiu para conectar advogadas e psicólogas voluntárias a mulheres que sofreram violência. E o setor privado também está se mobilizando. O Instituto Avon lançou a hashtag \#lsoladasSimSozinhasNão para ampliar a mensagem de prevenção e enfrentamento da violência contra mulher.

As medidas instituídas para fornecer apoio e proteção às vítimas de violência doméstica e familiar denotam que diversas entidades públicas e privadas estão preocupadas em conter os casos desse tipo de violência no Brasil (BRASIL, 2020; FBSP, 2020). Contudo, os dados disponíveis ainda são incipientes para analisar a eficiência dessas ações, uma vez que graças às medidas de isolamento social necessárias para reduzir a transmissão do coronavírus, o risco de violência contra a mulher se multiplicou e as denúncias reduziram, resultando em subnotificação dos casos, como já apontado por diversos autores (MARTINS et al., 2020; MONTEIRO et al., 2020b; VELOSO; MAGALHÃES, 2020).

\section{REDEFININDO AS DIFERENÇAS: UMA QUESTÃO RACIAL}

No contexto da pandemia de COVID-19, as mulheres negras vivenciam uma realidade distinta, algo que já era sinalizado em períodos anteriores à pandemia. As ENCICLOPÉDIA BIOSFERA, Centro Científico Conhecer - Jandaia-GO, v.18 n.35; p. 208 
mulheres negras se encontram mais vulneráveis nesse e em outros contextos, já que, em sua maioria, se encontram em espaços de trabalhos precarizados, apresentam baixos índices de escolaridade e altas taxas de chefia familiar, dentre tantas outras questões (FBSP, 2019b), como as dificuldades de acesso aos serviços de saúde.

Percebe-se um desequilíbrio racial no que diz respeito aos dados de violência contra a mulher, leia-se, entre mulheres não negras e mulheres negras. Nessa perspectiva, o Atlas da Violência (IPEA, 2020) apresenta dados da violência contra a mulher que informam que em 2018, 4.519 mulheres foram assassinadas no Brasil, o que representa uma taxa de 4,3 homicídios para cada 100 mil habitantes do sexo feminino. No cerne desses dados, no período entre 2017 e 2018, houve uma queda de $12,3 \%$ nos homicídios de mulheres não negras. Contudo, entre as mulheres negras essa redução foi somente de 7,2, o que aponta para esse último grupo como o mais vitimado. Ao analisar os dados do período entre 2008 e 2018, essa diferença fica ainda mais evidente: enquanto a taxa de homicídios de mulheres não negras caiu $11,7 \%$, a taxa entre as mulheres negras aumentou $12,4 \%$.

Martins et al. (2020) acrescentam que no Brasil, de acordo com dados produzidos pelos registros policiais e Secretarias Estaduais de Segurança Pública e/ou Defesa Social, entre os anos de 2017 e 2018, constatou-se que as vítimas de feminicídio, classificadas quanto à raça autodeclarada (considerando a etnia ou cor da pele) eram negras, em sua maioria. Conforme Sampaio e Meneghetti (2020, p.6), "o capitalismo como relação social produz o racismo, no caso da sociedade brasileira a marca fundamental é a violência". A ideologia de uma sociedade racista e patriarcal trata os corpos femininos como se não pertencessem às próprias mulheres. O sistema capitalista alimenta de forma muito perversa a ideia de objetificação e transforma corpos em mercadoria. As formas de opressão não são efeitos secundários, elas são inerentes à sociedade capitalista de forma a lhe estruturar. Assim, em uma sociedade heteronormativa de hierarquia racial branca, que carrega no âmbito da linguagem a reprodução do racismo, mulheres negras, pobres e/ou moradoras de periferias convivem constantemente com a sensação de insegurança, que por si só já é uma forma de dominação e opressão.

Conforme Bernardes (2020), a discussão sobre violência contra a mulher se tornou uma das mais importantes na agenda dos diversos movimentos feministas, 0 que teve como resultado a universalização do problema da violência doméstica e familiar como um problema de mulheres. Entretanto, a dimensão racial da violência não foi devidamente abordada dentro da construção desse processo.

No cerne das relações sociais brasileiras se difundiu a falsa ideia de que existe uma democracia racial, um mito de que as relações entre brancos e outros grupos étnico-raciais é praticamente igualitária. Essa falsa ideia expõe o caráter dissimulado do racismo brasileiro, que contrasta com o extermínio e com a dominação sistemática da população negra. Gonzaga e Cunha (2020, p.4), relatam que na "pandemia da COVID-19, alguns atores sociais afirmam que estamos no mesmo barco, uma versão desse mito, e sua falaciosa pretensão de que somos um só povo" no entanto os autores ressaltam que essa afirmativa não se sustenta, já que ao analisarem dados do Instituto Brasileiro de Geografia e estatística de 2015, perceberam que o acesso ao atendimento médico e a medicamentos da população preta e parda, $69,5 \%$ e $67,8 \%$ respectivamente, é menor do que a população branca, de $74,8 \%$. 
Levando em consideração a questão de raça/cor, Santos et al. (2020) apresentam dados percentuais referentes a casos leves de COVID-19 em alguns dos estados brasileiros: no estado de Pernambuco, $60,5 \%$ dos casos de infecção pelo vírus ocorreram em negros (pretos e pardos); no Rio Grande do Norte $39 \%$ dos casos; em Alagoas $66,5 \%$. No perfil dos óbitos verificou-se que $68 \%$ das vítimas fatais do coronavírus foram negros em Alagoas; $66 \%$ no Paraná; 37\% no Rio Grande do Norte; e 5\% no Rio Grande do Sul. Contudo, são altos os percentuais de não preenchimento do quesito raça/cor por parte dos profissionais de saúde. Se todos os quesitos fossem registrados, o panorama das desigualdades raciais em relação aos casos de COVID-19 estaria mais evidente.

Uma análise publicada em forma de ensaio científico pela Fundação Oswaldo Cruz realizou uma demarcação social do COVID-19 no Brasil, relatando que nas capitais do Brasil a disseminação do coronavírus debutou nos bairros mais ricos e migrou para a periferia, com a maioria da população negra que utilizava ônibus superlotados para ir trabalhar (OLIVEIRA et al., 2020). Esses autores destacam que, apesar de a disseminação do vírus ter iniciado entre a população mais rica, ao mesmo tempo em que houve uma queda de internações e óbitos em brancos houve o aumento em negros.

Nas primeiras semanas epidemiológicas, a população branca representou $73 \%$ das internações e $62,9 \%$ dos óbitos. Meses depois houve queda de internações e óbitos em brancos e o aumento em negros até ocorrer quase uma paridade entre 0 número de casos. Já quanto ao número de óbitos, o de negros passou a superar o de brancos, ainda que a hospitalização não tenha acompanhado esta tendência. Isso demonstra a dificuldade de acesso da população negra aos serviços de saúde, principalmente leitos de UTI. No que diz respeito às mortes, os autores trazem que a proporção de óbitos em brancos é de $34,3 \%$, enquanto a de negros é de $57 \%$. Esse cenário expõe uma grande distinção nas chances de morte por COVID-19 segundo raça/cor: "um paciente negro analfabeto tem 3,8 vezes mais chances de morrer em relação ao branco com nível superior" (OLIVEIRA et al., 2020, p.10).

Ainda no que refere às desigualdades sociais durante a crise gerada pela COVID-19, Estrela et al., (2020) citam as diferenças na forma como são tratados os casos entre pessoas negras e brancas. As diferenças ficam evidentes desde o acesso a testes para detecção do vírus até o tratamento da infecção, processo que é facilitado pelo poder aquisitivo do indivíduo que pode suprir as dificuldades econômicas e de saúde que a doença gera. Sendo assim os mais pobres e os negros estão claramente mais vulneráveis às consequências da COVID-19, já que o preconceito de raça e falta de acesso aos serviços de saúde e segurança geram impactos ainda maiores. A não inclusão da questão racial nos registros oficiais e nos moldes institucionais faz com que não seja conhecido 0 acesso à verdadeira extensão da exclusão da população negra (OLIVEIRA et al., 2020).

É preciso reconhecer cada uma das vítimas da COVID-19 e admitir que boa parte é vítima não apenas do novo coronavírus, mas, principalmente, do racismo estrutural que coloca pessoas negras em posições de maior vulnerabilidade, aumentando a suscetibilidade ao contágio daquelas que têm menor acesso às possibilidades de prevenção e tratamento; além de acentuar fragilidades, inseguranças e desamparo na obtenção de meios de sobrevivência para aqueles que já se encontravam afastados de direitos básicos (GONZAGA; CUNHA, 2020).

Assim, segundo Gonzaga e Cunha (2020), a crise sanitária em curso tem mostrado as complexas experiências das mulheres negras a partir de suas posições ENCICLOPÉDIA BIOSFERA, Centro Científico Conhecer - Jandaia-GO, v.18 n.35; p. 210 
nas estruturas de poder, pois, elas compõem um dos grupos sociais mais impactados pela pandemia da COVID-19, ao mesmo tempo em que assumem posições de protagonistas em ações de prevenção e cuidado de suas famílias e comunidades. O desejo de alguns no contexto de pandemia seria voltar à normalidade perdida, outros dizem que vivem o novo normal, contudo ambos os cenários não são seguros para as vidas negras. Há um desmonte na produção de informação a partir do não preenchimento do quesito raça/cor em registros oficiais de órgãos estatais, além da não divulgação de dados já existentes. E na pandemia, a maioria dos estados brasileiros imprimiu uma cortina de fumaça que oculta informações étnico-raciais das pessoas infectadas pelo novo Coronavírus, assim como das suas vítimas fatais. Essa escolha política permite identificar os meandros sofisticados de sustentação de políticas que não levam em consideração a questão racial, ampliadas pela atual pandemia.

\section{CONSIDERAÇÕES FINAIS}

A crise sanitária gerada pela pandemia de COVID-19 explicitou um cenário pré-existente de desigualdades sociais presentes na sociedade, questão essa que pode ser representada por uma junção de problemáticas enfrentadas principalmente pela população feminina e negra no Brasil, grande parte em situação de vulnerabilidade social.

As medidas de isolamento social e quarentena devido à pandemia reavivaram o debate sobre a violência doméstica e familiar contra a mulher. Esse debate já era presente na sociedade brasileira, mas ganhou visibilidade devido à maior frequência da convivência familiar em seus domicílios e as dificuldades de acesso a serviços de saúde e segurança da mulher, por diversos motivos relacionados às tentativas de contenção da disseminação da COVID-19. Esse cenário não só aumentou o risco de violência contra a mulher como gerou uma redução nas denúncias, gerando uma subnotificação do fenômeno.

Dessa maneira, as estatísticas sobre a violência contra a mulher produzidas durante a pandemia não permitem uma aproximação apurada do fenômeno, além de diluírem a diversidade das vítimas em uma categoria unívoca: mulher. Mas que mulher é essa? Qual a sua condição social? Qual a cor da sua pele? O fato de não existir um controle sobre a questão social e racial das mulheres vítimas de violência dificulta a construção de políticas públicas que auxiliem efetivamente no enfrentamento desse problema.

Os dados sobre as condições de vulnerabilidade social vivenciadas pelas mulheres negras no cenário pré-pandemia permitem prospectar que essas vulnerabilidades se tornaram ainda mais intensas no período pandêmico, provocando um cruzamento de opressões sobre essas mulheres, agravadas pela crise sanitária e generalizada. Nesse sentido, é necessário que as políticas de combate à violência contra a mulher tenham como base a diversidade característica das mulheres brasileiras, diferenças essas que não se restringem ao gênero, mas envolvem diversas outras características, como é o caso da raça, o que tem colocado as mulheres negras em situação de extrema vulnerabilidade e invisibilidade durante a pandemia.

\section{REFERÊNCIAS}

AKOTIRENE, C. Interseccionalidade. São Paulo: Pólen, 2019. 
BARBOSA, J. P. M.; LIMA, R. de C. D.; MARTINS, G. de B.; LANNA, S, D; ANDRADE, M. A. C. Interseccionalidade e outros olhares sobre a violência contra mulheres em tempos de pandemia pela covid-19. Scielo Preprints, 21p. 2020. Disponível em: https://preprints.scielo.org/index.php/scielo/preprint/view/328. Acesso em 21/01/2021.

BARDIN, L. Análise de conteúdo. São Paulo: Edições 70, 2011.

BARROSO, M. F. Violência estrutural contra mulheres em Belo Monte: o que os dados oficiais (não) revelam. Revista em Pauta, v. 17, n. 43, p. 140-154, 2019. Disponível em: https://doi.org/10.12957/rep.2019.42509. Acesso em 11/02/2020.

BERNARDES, M. N. Questões de raça na luta contra a violência de gênero: processos de subalternização em torno da Lei Maria da Penha. Revista Direito GV, v. 16, 3, São Paulo, 2020. Disponível em: https://doi.org/10.1590/2317-6172201968. Acesso em 28/01/2021.

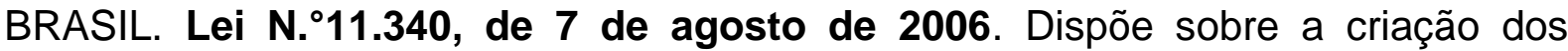
Juizados de Violência Doméstica e Familiar contra a Mulher; e estabelece medidas de assistência e proteção às mulheres em situação de violência doméstica e familiar. Brasília, DF, 2006. Disponível em: http://www.planalto.gov.br/ccivil_03/_Ato20042006/2006/Lei/L11340.htm\#: :text=Lei\%20n\%C2\%BA\%2011.340\&text=Cria\%20mec anismos\%20para\%20coibir\%20a,do\%20\%C2\%A7\%208\%C2\%BA\%20do\%20art.

Acesso em 14/02/2020.

BRASIL. Lei № 14.022, de 7 de Julho de 2020. Dispõe sobre medidas de Enfrentamento à violência doméstica e familiar contra a mulher e de enfrentamento à violência contra crianças, adolescentes, pessoas idosas e pessoas com deficiência durante a emergência de saúde pública de importância internacional decorrente do coronavírus responsável pelo surto de 2019. Brasília, DF, 2020. Disponível em: http://www.planalto.gov.br/ccivil_03/_ato2019-2022/2020/lei/L14022.htm. Acesso em 14/02/2021.

BRASIL. Ministério da Mulher, da Família e dos Direitos Humanos. Violência contra mulher. 2020. Disponível em: https://www.gov.br/mdh/pt-br/acesso-ainformação/ligue-180. Acesso em 11/02/2021.

BRASIL. Ministério da Mulher, da Família e dos Direitos Humanos. Denúncias registradas pelo ligue 180 aumentam nos quatro primeiros meses do ano. 2020. Disponível: https://www.gov.br/mdh/pt-br/assuntos/noticias/20202/maio/denuncias-registradas-pelo-ligue-180-aumentam-nos-quatro-primeirosmeses-de-2020. Acesso em:12/02/2021.

BRASIL. Agência. Lei Maria da Penha: Subnotificações escondem número real da violência. 2020. Disponível: https://agenciabrasil.ebc.com.br/direitoshumanos/noticia/2020-08/lei-maria-da-penha-subnotificacoes-escondem-numeroreal-da. Acesso em 11/02/2021. 
CAMPOS, B., TCHALEKIAN, B. PAIVA, V. Violência contra a mulher: vulnerabilidade programática em tempos de SARS-COV-2/ Covid-19 em São Paulo. Psicologia \& Sociedade, v.32, n.1, p.1-20, 2020. Disponível em: https://doi.org/10.1590/18070310/2020v32240336. Acesso em 11/02/2020.

CARNEIRO, S. Mulheres Negras e Violência Doméstica: decodificando os números. Geledés - Instituto da Mulher Negra, São Paulo, v. 1, n. 1, 360p. 2017. Disponível em: https://www.geledes.org.br/wp-content/uploads/2017/03/e-BOOKMULHERES-NEGRAS-e-VIOL\%C3\%8ANCIA-DOM\%C3\%89STICA-decodifancandoos-n\%C3\%BAmeros-isbn.pdf. Acesso em 27/01/2021.

CURIA, B. G.; DIAS, V G.; ZAMORA, J. C.; RUOSO, A.; LIGÓRIO, I. S. et al. Produções Científicas Brasileiras em Psicologia sobre Violência contra Mulher por Parceiro Íntimo. Psicologia: Ciência e Profissão, v. 40, n.1, p. 1-19, 2020. Disponível em: http://dx.doi.org/10.1590/1982-3703003189184. Acesso em: $11 / 02 / 2020$.

ESTRELA, F. M.; SOARES, C. F.; CRUZ, M. A.; SILVA, A. F.; SANTOS, J. R. L.; et al. Pandemia da Covid-19: refletindo as vulnerabilidades à luz do gênero, raça e classe. Revista Ciência Coletiva, v. 25, n.9, p. 3431- 3436, 2020. Disponível em: https://doi.org/10.1590/1413-81232020259.14052020. Acesso em 15/02/2021.

FBSP - Fórum Brasileiro de Segurança Pública .; Anuário Brasileiro de Segurança Pública 2019, ano 13, p. 108-115, 2019a. Disponível em: https://www.forumseguranca.org.br/wp-content/uploads/2019/10/Anuario-2019FINAL_21.10.19.pdf. Acesso em 22/01/2021.

FBSP- Fórum Brasileiro de Segurança Pública.; Anuário Brasileiro de Segurança Pública 2020, ano 14 p.13-38, 2020. Disponível em: https://forumseguranca.org.br/anuario-brasileiro-seguranca-publica/. Acesso em $13 / 02 / 2021$.

FBSP - Fórum Brasileiro de Segurança Pública.; Visível e Invisível: A vitimização de mulheres no Brasil 2019b - 2 a Edição, p.25-42, 2019b. Disponível em: https://www.forumseguranca.org.br/wp-content/uploads/2019/02/relatorio-pesquisa2019-v6.pdf. Acesso em 27/01/2021.

GIL, A. C. Métodos e técnicas de pesquisa social. 7ª̣ ed. São Paulo: Atlas, 2019.

GONZAGA, P. R. B.; CUNHA, V. M.; Uma Pandemia Viral em Contexto de Racismo Estrutural: Desvelando a Generificação do Genocídio Negro. Dossiê Covid-19. Psicologia: Ciência e Profissão, v. 40, p. 1-17, 2020. Disponível em: https://doi.org/10.1590/1982-3703003242819. Acesso em: 05/02/2021

IPEA - Instituto de Pesquisa Econômica Aplicada.; Atlas da violência 2020. Brasília-DF. $\quad$ p. 34-47, 2020. Disponível em: https://dx.doi.org/10.38116.riatlasdaviolencia2020. Acesso em: 25/01/2021. 
MARCONI, M. de A.; LAKATOS, E. M. Metodologia científica. Ed. 7, São Paulo: Atlas, 2018.

MARTINS. A. M. E. B. L.; FONSECA, J. R.; MOURA, R. S. D.; GUSMÃO, M. S. F.; NEVES, P. C. V.; et al. Violência contra a mulher em tempos de pandemia da covid19 no Brasil: revisão narrativa de literatura. Revista Enfermagem Atual In Derme, Edição especial Covid-19, v. 93, p. 1-16, 2020. Disponível em: https://doi.org/10.31011/reaid-2020-v.93-n.0-art.828. Acesso em 02/02/2020.

MONTEIRO, S. A. S.; SILVA, C. R.; RIBEIRO, P. R. M. Investigação da violência de gênero na América Latina e Caribe: pequena revisão da literatura (2017-2019). Política e Gestão Educacional, v. 24, n. 2, p. 649-667, 2020a. Disponível em: https://doi.org/10.22633/rpge.v24i2.13812652. Acesso em: 25/01/2021.

MONTEIRO, S. A. S.; YOSHIMOTO, E.; RIBEIRO, P. R. M. A produção acadêmica sobre a questão da violência contra a mulher na emergência da pandemia da COVID-19 em decorrência do isolamento social. DOXA: Revista Brasileira De Psicologia e Educação, v. 22, n. 1, p. 152-170, 2020b. Disponível em: https://doi.org/10.22633/rpge.v24i2.13812652. Acesso em: 05/02/2021.

OKABAYASHI, N. Y. T.; TASSARA, I. G.; CASACA, M. C. G.; FALCÃO, A. de A.; BELLINI, M. Z. Violência contra a mulher e feminicídio no Brasil - impacto do isolamento social pela COVID-19. Brazilian Journal of health Review. Curitiba, v. 3, n. 3, p.4511-4531, 2020. Disponível em: https://doi.org/10.34119/bjhrv3n3-049. Acesso em 27/01/2021.

OLIVEIRA, P. P. Discursos sobre a masculinidade. Estudos Feministas, v. 06, n. 01, p. 91-112, 1998. Disponível em: https://doi.org/10.1590/\%25x. Acesso em: $11 / 02 / 2021$.

OLIVEIRA, R. G.; CUNHA, A. P.; GADELHA, A. G. dos. S.; CARPIO, C. G.; OLIVEIRA, R. B.; et al. Desigualdades raciais e a morte como horizonte: considerações sobre a COVID-19 e o racismo estrutural. Caderno de Saúde Pública, v. 36, n. 9, 2020. Disponível em: https://doi.org/10.1590/0102311x00150120. Acesso em 14/02/2021.

SAMPAIO, S. S; MENEGHETTI, G. Entre a vida e a morte: Estado, racismo e a "pandemia do extermínio" no Brasil. Revista katálysis, v. 23, n. 3, p. 635-647, 2020. Disponível em: http://dx.doi.org/10.1590/1982-02592020v23n3p635. Acesso em: 28/01/2021.

SANTOS, H. L. P. C.; MACIEL, B. M.; SANTOS K. R.; CONCEIÇÃO, C. D. V. S. OLIVEIRA, R. S.; et al. Necropolítica e reflexões acerca da população negra no contexto da pandemia da COVID-19 no Brasil: uma revisão bibliográfica. Ciência \& Saúde Coletiva, v. 25, s.2, p. 1-14, 2020. Disponível em: https://doi.org/10.1590/1413-812320202510.2.25482020. Acesso em 28/01/2021.

VELOSO, R. C.; MAGALHÃES, T, V. A pandemia da Covid -19 e suas implicações no âmbito da violência de gênero. Revista de Criminologias e Políticas Criminais. ENCICLOPÉDIA BIOSFERA, Centro Científico Conhecer - Jandaia-GO, v.18 n.35; p. 214 2021 
Encontro Virtual, v. 6, n. 2 p. 37-53, 2020. Disponível em: http://dx.doi.org/10.26668/IndexLawJournals/2526-0065/2020.v6i2.7060. Acesso em: $28 / 01 / 2021$

VIGOYA, M. V. L'intersectionnalité au prisme du féminisme latino-américain. Raisons Politiques, n. 58, v. 02, p. 39-54, 2015 . Disponível em https://www.cairn.info/revue-raisons-politiques-2015-2-page-39.htm, acesso em $09 / 03 / 2021$

VIGOYA, M. V. La interseccionalidad: una aproximación situada a la dominación. Debate Feminista, n. 52, p. 01-17, 2016. Disponível em https://www.sciencedirect.com/science/article/pii/S0188947816300603. Acesso em 09/03/2021. 